\title{
HISTÓRIAS EM QUADRINHOS COMO RECURSO DIDÁTICO PARA O ENSINO DO CORPO HUMANO EM ANOS INICIAIS DO ENSINO FUNDAMENTAL
}

\author{
Comic books as a teaching resource for teaching \\ the human body in initial years of Elementary School
}

\author{
Elisa Mári Kawamoto ${ }^{1}$ • Luciana Maria Lunardi Campos ${ }^{2}$
}

\begin{abstract}
Resumo: Os recursos didáticos envolvem diversos elementos utilizados como suporte na organização do processo de ensino-aprendizagem. Dentre eles, estão as histórias em quadrinhos, envolvendo aspectos visuais, cognitivos e criativos, que fornecem uma forma alternativa de complementar as aulas teóricas. O objetivo deste estudo foi elaborar e avaliar uma história em quadrinhos intitulada "Corpo humano", com enfoque nos sistemas circulatório, digestório, nervoso e respiratório, de modo a fornecer uma alternativa de recurso didático para o ensino do conteúdo em anos iniciais. O material foi avaliado junto a estudantes de um $5^{\circ}$ ano do Ensino Fundamental de uma escola pública do interior do estado de São Paulo, por meio de utilização de questionários. O gibi se mostrou válido como recurso didático complementar para o aprendizado dos alunos, possibilitando a reflexão sobre a pertinência do desenvolvimento e da utilização das histórias em quadrinhos para o ensino de ciências nas séries iniciais.
\end{abstract}

Palavras-chave: Ensino Fundamental. Saúde. Recurso didático. Ensino de ciências. História em quadrinhos.

\begin{abstract}
Teaching resources involve different elements used to support the organization of teaching and learning. Among these are the comic books, involving visual aspects, both cognitive and creative, that provide an alternative way to complement the lectures. The aim of this study was to develop and evaluate a comic book entitled "Human Body", focusing on the circulatory, digestive, nervous and respiratory systems, to provide an alternative resource for the teaching of the content in the initial years. The material was evaluated with students of the 5th year of elementary education at a public school in the state of São Paulo, through the use of questionnaires. The comic book proved to be valid as a complementary teaching resource for learning in students, enabling reflection on the relevance of the development and use of comics to science education in the initial years.
\end{abstract}

Keywords: Elementary school. Health. Teaching resource. Science teaching. Comic book.

\footnotetext{
${ }^{1}$ Universidade Federal de São Paulo (Unifesp), Departamento de Farmacologia, Rua Botucatu, 862, Edificio Leal Prado, $1^{\circ}$ andar, Vila Clementino, CEP 04023-062, São Paulo, SP, Brasil. E-mail: elisakawamoto@gmail.com

${ }^{2}$ UNESP - Univ Estadual Paulista, Instituto de Biociências, Departamento de Educação, Botucatu, SP, Brasil.
} 
Kawamoto, E. M.; Campos, L. M. L.

\section{Introdução}

O ensino de Ciências Naturais é um espaço privilegiado em que as diferentes explicações sobre o mundo, os fenômenos da natureza e as transformações produzidas pelo homem podem ser expostos e comparados, possibilitando que os estudantes compreendam a natureza como um todo dinâmico e o ser humano como parte integrante e agente de transformações do mundo em que vive. Nesse período é proposto o desenvolvimento de diferentes blocos temáticos, dentre eles "Ser Humano e Saúde", embora "Saúde" seja também proposto como um dos Temas Transversais (BRASIL, 1998).

O ensino de temas de saúde envolve a atuação sobre o conhecimento dos alunos, para que eles desenvolvam juízo crítico e capacidade de intervenção sobre suas vidas e sobre o ambiente com o qual interagem. Ele requer que o estudante conheça o seu próprio corpo e possa cuidar-se, valorizando e adotando hábitos saudáveis, como um dos aspectos, e agindo com responsabilidade em relação à sua saúde e à saúde coletiva.

O estudo do corpo humano nos anos iniciais do Ensino Fundamental pode instigar os estudantes, estimulando-os a questionar e voltar seu olhar para seu próprio corpo, que está em fase de constantes mudanças, e ampliar conhecimentos científicos previamente adquiridos (RABELLO, 1994), contribuindo para que o indivíduo reflita sobre mudanças de hábitos e formas de pensamento.

A abordagem do tema "corpo humano" deve ser clara, possibilitando o aumento de sua complexidade em anos posteriores (BRASIL, 1998; KRASILCHIK, 2005), e deve favorecer a compreensão de transformações e de processos que ocorrem em diversos sistemas do nosso corpo, considerando-se que ele é constituído por diversas partes inter-relacionadas, com sistema e órgãos responsáveis por uma ou mais atividades, além de milhares de reações químicas que acontecem a todo instante dentro dele (para captar energia, movimentar os músculos, recuperar-se de ferimentos e doenças ou manter-se na temperatura adequada à vida) (ZORZETTO, 1999). Não importa por qual sistema do corpo humano se iniciem os estudos, mas, sim, que seja favorecida a compreensão da função de cada sistema e órgão, assegurando-se a abordagem das relações entre os sistemas e garantindo-se a construção da noção de corpo como todo integrado e dinamicamente articulado à vida emocional e ao meio físico e social (BRASIL, 1998).

No entanto, verifica-se que o ensino de Ciências Naturais em anos iniciais vem sendo realizado de modo superficial, reprodutivo e com poucas atividades (BONANDO, 1994 apud OVIGLI; BERTUCCI, 2009). Muitas vezes, ensina-se Ciências aprisionando o aluno na relação "pergunta-resposta", sem que ele consiga interagir com colegas para construir conhecimentos (OLIVEIRA, 2009). Ainda, reconhece-se que a pouca relação estabelecida entre aulas de Ciências, realidade dos estudantes e seus interesses, apontada há muitos anos (KRASILCHICK, 1987), não foi plenamente superada, levando a um aprendizado disperso, à passividade do aluno e dificultando a elaboração de ideias e a construção de conhecimentos sobre assuntos estudados.

No entanto, o ensino do corpo humano em séries iniciais vem sendo realizado, muitas vezes, de forma fragmentada, puramente nominal e sem muita conexão entre os sistemas. Tal organização pedagógica pode dificultar a compreensão da criança de que seu corpo trabalha como um todo, com integração entre todos os seus órgãos e sistemas (RABELLO, 1994). 
Histórias em Quadrinhos como recurso ...

A utilização de diferentes procedimentos e recursos para o ensino de Ciências nas séries iniciais é abordada por Campos et al. (2011).

Os Parâmetros Curriculares Nacionais de Ciências Naturais (BRASIL, 1998) orientam o uso de diversas fontes de informação nas aulas de Ciências e de recursos, que deve figurar como preocupação central por parte dos professores:

Além do livro didático, outras fontes oferecem textos informativos: enciclopédias, livros paradidáticos, artigos de jornais e revistas, folhetos de campanhas de saúde, de museus, textos da mídia informatizada, etc. É importante que o aluno possa ter acesso a uma diversidade de textos informativos, pois cada um deles tem estrutura e finalidade próprias. (BRASIL, 1998, p. 81)

Os recursos didáticos envolvem uma diversidade de elementos utilizados como suporte experimental na organização do processo de ensino e de aprendizagem, com a finalidade de servir de interface mediadora para facilitar na relação entre professor, aluno e o conhecimento em um momento preciso da elaboração do saber. São criações pedagógicas desenvolvidas para facilitar o processo de aquisição do conhecimento (PAIS, 2000).

Pode-se compreender que os recursos didáticos têm sido concebidos como "instrumentos modernizadores das práticas escolares e, consequentemente, efetivadores de um ensino de mais qualidade" (FISCARELLI, 2008, p. 85). Dentre as opções de recursos didáticos disponíveis para os professores de Ensino Fundamental, estão as histórias em quadrinhos.

\section{Histórias em quadrinhos como recurso didático}

Apesar de muito antiga, a história em quadrinhos (HQ) constitui um mundo de encanto para as diversas faixas etárias, em especial para o segmento infanto-juvenil, que vê, nesta linguagem, uma forma muito interessante para expressar sentimentos e emoções (LISBÔA; BOTTENTUIT JUNIOR; COUTINHO, 2009).

Mediante sua linguagem própria, as histórias contadas por meio de sequências de imagens se tornaram uma das formas mais simples e diretas para a transmissão de ideias, oferecendo inúmeras possibilidades para o exercício da leitura. Além disso, contribuem para o desenvolvimento da competência de interação entre leitor e texto por meio de um processo de descoberta, tornando a leitura uma tarefa desafiadora e, até mesmo, lúdica (VERGUEIRO, 2004), uma vez que também desenvolvem a imaginação para a produção de histórias; a interação entre os estudantes, e uma ampla visão e análise da linguagem escrita e extraverbal (RITTES, 2006).

O professor, adaptando os quadrinhos ao seu planejamento (objetivos e conteúdos), pode utilizar esse recurso, possibilitando novo estímulo ao aluno e, consequentemente, tornando sua aula mais interessante, além de poder observar melhor a aprendizagem de seus estudantes (RITTES, 2006; VERGUEIRO, 2004).

Estudos desenvolvidos sobre o uso de quadrinhos como recurso para o ensino de Ciências (por exemplo: GONÇALVES; MACHADO, 2005; GONZÁLEZ-ESPADA, 2003; 
Kawamoto, E. M.; Campos, L. M. L.

KAMEL, 2006; SOARES, 2004; TESTONI, 2004; VÍLCHEZ-GONZÁLEZ; PERALEZPALACIOS, 2006; WORNER; ROMERO, 1998) apresentam discussões sobre diferentes aspectos da utilização deste recurso, tais como: atividades realizadas (leitura, construção de história em quadrinhos (HQ) por parte dos alunos, análise de conteúdos científicos presentes em gibis comerciais); limitações (como a imagem distorcida da Ciência presente em seus enredos) e potencialidades (contribuição para a divulgação científica e o ensino de conteúdos conceituais de forma bem humorada), entre outros.

Kamel (2006), analisando as potencialidades das histórias em quadrinhos da Turma da Mônica, de autoria de Maurício de Sousa, verificou que as publicações escolhidas contemplam os três grupos temáticos que são trabalhados nas aulas de Ciências Naturais do Ensino Fundamental (com base nos Parâmetros Curriculares Nacionais, PCN): ambiente (que abrange conhecimentos sobre as interações entre seus componentes, ou seja, seres vivos, ar, água, solo, luz e calor); ser humano e saúde; e recursos tecnológicos e fontes de energia. A autora considera que as histórias em quadrinhos se mostraram como preciosos subsídios didáticos para introduzir, elaborar e complementar conhecimentos científicos, e elas podem e devem ser utilizadas para promover e desenvolver competências cognitivas por meio do processo de conclusão e abstração, pois, muitas vezes, uma simples forma ou um traço é suficiente para desencadear uma conclusão, possibilitando que o leitor extrapole o óbvio e crie novas hipóteses. Além disso, a ilustração associada ao texto constitui uma técnica notável, segundo ela, para despertar o interesse e compreensão das crianças.

O reconhecimento dos quadrinhos como recurso didático e a necessidade de constante aprimoramento de metodologias que acompanhem o interesse dos estudantes levaram à elaboração e ao desenvolvimento do presente estudo ${ }^{3}$.

O objetivo deste estudo foi elaborar e avaliar uma história em quadrinhos com a abordagem de conteúdos relacionados aos sistemas circulatório, digestório, nervoso e respiratório, do tema "Corpo humano", no ensino de anos iniciais. O gibi foi intitulado: "Corpo humano - uma história em quadrinhos".

\section{A elaboração}

O desenvolvimento da história em quadrinhos envolveu a elaboração de uma versão preliminar, uma avaliação e a elaboração da versão final.

Para a elaboração da versão preliminar, foram realizadas:

\section{a) Identificação e seleção de conceitos e conteúdos}

A partir da análise de livros didáticos de ciências utilizados atualmente nas séries iniciais, foram identificados e selecionados os conteúdos abordados. Foram consultados os seguintes livros:

- Coleção de Olho no futuro: $4^{a}$ série, Marinez Meneghello;

- Porta Aberta - 50 Ano - Ciências Naturais, Sueli Fanizzi e Ângela Gil;

${ }^{3}$ Kawamoto (2009). 
- Coleção Ciências para você: $4^{a}$ série, Márcia Santos Fonseca, Maria Hilda de Paiva Andrade, Marta Bouissou Morais, Maurício Bouissou Moraes.

Para a seleção dos conteúdos, foram verificados quais estavam presentes nos livros didáticos analisados, considerando-se a finalidade complementar do gibi, e foram selecionados aqueles relacionados, sobretudo, com a anatomia dos órgãos, sendo estes o ponto de partida para a abordagem do conteúdo, visando construir uma relação entre a estrutura e a função dos órgãos. Os conteúdos definidos foram os sistemas: nervoso, digestório, respiratório e circulatório, e os órgãos dos sentidos.

Os conteúdos selecionados foram: Estrutura e função do Sistema Nervoso; Órgãos do Sentido (visão, audição, olfato, paladar e tato); Estrutura e função do Sistema Digestório; Trajetória dos alimentos pelo sistema digestório; Estrutura e função do Sistema Respiratório; Trajetória do ar no Sistema Respiratório; Estrutura e função do Sistema Circulatório; Células responsáveis pela defesa, transporte de oxigênio e coagulação do sangue, e Trajetória do sangue pelo corpo.

\section{b) Organização do roteiro geral da história}

A organização do roteiro partiu de uma ideia básica que poderia ser extrapolada para quatro histórias, cada uma se referindo a um sistema do corpo humano.

O gibi foi dividido em cinco partes: uma parte envolvendo a história inicial comum a todas as histórias e quatro partes, uma para cada sistema. Assim, de modo a interligar os sistemas, o roteiro foi elaborado tendo um contexto geral único, que seria o ponto de partida de todas as histórias.

Precauções para adequação à linguagem foram tomadas, considerando-se a faixa etária, e os personagens foram desenvolvidos para terem uma idade semelhante à do públicoalvo, sendo utilizadas cores fortes em toda ilustração para despertar o interesse à leitura.

Foram criados seis personagens: cinco crianças representavam indivíduos com faixa etária semelhante ao do público-alvo (Carlos, Elisa, Mariana, Samara e Tassiani) e um adulto (Sr. Mágico).

A história começa em um parque de diversões, onde as crianças estão procurando um brinquedo para se divertirem juntas. Após muita discussão, decidem ir para uma atração intitulada "o corpo", dirigida pelo sr. Mágico. O sr. Mágico faz uma apresentação de sua atração, informando que esta era encantada para funcionar como o corpo humano, e que o prêmio para quem conseguisse desvendar os segredos de "O corpo" era algo muito valioso. As crianças ficam muito animadas com tais informações e resolvem adentrar na atração. Ao entrarem, são enviadas para outro local, uma sala, que contém quatro portas, cada uma representando um sistema distinto (circulatório, digestório, nervoso e respiratório).

As crianças se dividem para enfrentar o desafio: Elisa e Samara escolhem o sistema circulatório; Carlos, o sistema respiratório; Tassiani, o sistema digestório, e Mariana, o sistema nervoso. Neste ponto encerra-se a primeira parte do gibi. As partes consequentes continuam a partir deste mesmo ponto, de forma que os estudantes podem escolher por qual sistema desejam iniciar. É importante ressaltar que, apesar dessa divisão de sistemas, todas as histórias possuem alguma conexão umas com as outras.

No sistema circulatório, Elisa e Samara realizam o percurso do sangue, iniciando sua trajetória no coração. Para passar por todos os "pontos" do trajeto (compartimentos do 
Kawamoto, E. M.; Campos, L. M. L.

coração, pulmão e sistema digestório - para aquisição de nutrientes), elas tiveram de responder a algumas perguntas e realizar algumas tarefas, como, por exemplo, trocas de gases com o pulmão. Cada pergunta fazia relação com alguma informação e curiosidade a respeito do sistema/órgão (por exemplo: quantidade de batimentos do coração). No final da trajetória, encontram o Sr. Mágico, que sugere um desafio final (que deve ser realizado pelos leitores): um labirinto.

No sistema respiratório, Carlos, ao entrar em uma sala, se depara com muitos pelos (pois se encontra na região do nariz) e, ao responder corretamente a uma pergunta encontrada no ambiente, consegue passagem ao caminho que o levará para os outros pontos do sistema (faringe, traqueia, pulmão), que serão "abertos" após a resposta correta das perguntas e realização de tarefas (como, por exemplo, trocas de gases com o sistema circulatório). As perguntas, como em todos os sistemas, têm relação com o sistema em questão, com inclusão de algumas curiosidades. No final do trajeto, Carlos encontra novamente o Sr. Mágico, que sugere um desafio final, que também deve ser realizado pelos leitores: decifrar as frases através de um código.

No sistema digestório, Tassiani vai parar na boca e, assim como nos outros sistemas mencionados anteriormente, ela deverá responder a perguntas e realizar tarefas (como, por exemplo, quebrar nutrientes) para poder realizar toda a trajetória do sistema (boca, faringe, esôfago, estômago, intestino delgado). O intestino delgado é apresentado pelo Sr. Mágico, que aparece no final da trajetória, sugerindo um desafio final a ser realizado pelos leitores: um caça-palavras.

No sistema nervoso, Mariana entra em uma sala decorada por neurônios, onde se encontra um computador, que mostra um sistema de monitoramento de todos os sistemas. Uma opção que aparece no visor é "Conhecer o Sistema Nervoso", sendo esta a escolhida. Ao selecionar, uma "videoaula" aparece, tendo como atores, Carlos, Elisa e Samara, que explicam as funções e a estrutura do sistema nervoso central e periférico, finalizando com os órgãos do sentido. Após assistir a aula, o Sr. Mágico aparece, sugerindo um desafio para o leitor: palavras cruzadas.

Vencidas as etapas de todos os sistemas, os personagens comemoram, por terem vencido o desafio. No entanto, descobrem que, na verdade, estavam desmaiados e que teoricamente, haviam sonhado. As crianças ficam um pouco confusas, mas procuram outro brinquedo para se divertirem. Atrás de uma árvore, o Sr. Mágico observa tudo e, finalmente, conta qual era o prêmio valioso de sua atração: o conhecimento.

\section{A avaliação: processo e resultados}

Para a versão preliminar, foram impressas três cópias, que foram utilizadas no estudo com a leitura em grupo e rotatividade das cópias entre os 18 alunos. A avaliação do material foi realizada por 18 estudantes do $5^{\circ}$ ano do Ensino Fundamental de uma escola pública e pela professora responsável pela classe, por meio de questionários.

A avaliação pelos estudantes foi realizada sob a supervisão da professora responsável pela classe, em data e horário previamente agendados. Inicialmente, foi realizado um breve levantamento do conhecimento prévio dos estudantes sobre órgãos do corpo humano, por 
Histórias em Quadrinhos como recurso ...

meio de um questionário com seis questões de múltipla escolha sobre: o órgão responsável pelas trocas de ar; órgão do sentido, órgãos do sistema digestório; número de partes em que o coração pode ser dividido; o nome da célula que realiza a coagulação sanguínea; principal célula do sistema nervoso.

Em relação aos conhecimentos prévios dos alunos, pelas respostas apresentadas, verificou-se que os estudantes tinham noção do assunto abordado, uma vez que já haviam assistido às aulas referentes ao conteúdo.

Os resultados obtidos foram sintetizados na Tabela 1.

Tabela 1. Conhecimento prévio dos alunos

\begin{tabular}{lccc}
\hline \multicolumn{1}{c}{ Questões } & \multicolumn{3}{c}{ Respostas } \\
\cline { 2 - 4 } & Corretas & Incorretas & Não respondeu \\
\hline Órgão responsável pelas trocas de ar & 17 & 00 & 01 \\
Órgão de sentido & 17 & 01 & 00 \\
Sistema digestório & 17 & 00 & 01 \\
Divisão do coração & 12 & 06 & 00 \\
Célula que realiza a coagulação sanguínea & 07 & 11 & 00 \\
Principal célula do sistema nervoso & 11 & 06 & 01 \\
Total & 80 & 24 & 03 \\
\hline
\end{tabular}

Fonte: elaborado pelas autoras.

Em relação às respostas incorretas:

- divisão do coração: seis estudantes alegaram que o "o coração se dividia em dois" (direito e esquerdo);

- célula que realiza a coagulação sanguínea: cinco estudantes indicaram hemácia; quatro responderam glóbulo vermelho e dois apontaram glóbulo branco, e

- principal célula do sistema nervoso: quatro estudantes responderam glândula e dois indicaram hemácia.

Verifica-se que o número maior de acertos foi sobre conteúdos relacionados ao sistema respiratório, órgãos de sentido e digestório.

\section{A leitura do gibi}

Os estudantes indicaram entusiasmo ao perceberem que o material era um gibi e, durante a leitura, manifestaram interesse e motivação para a atividade, sendo tal fato demonstrado por meio da utilização de expressões como: "Que legal, um material diferente!"; "Gosto muito de desenhos em quadrinhos!"; "Acho muito mais legal estudar assim."

Logo de início houve manifestação de interesse pela realização da atividade em grupo, visto que o número de gibis não era suficiente para uma leitura individual. As expressões utilizadas por eles denotavam apreciação pelo material que estava sendo apresentado, tanto em relação ao desenho quanto ao conteúdo. Tal condição foi constatada pelos elogios dos estudantes aos desenhos e pelos comentários que indicavam que as informações contidas no gibi eram desconhecidas e interessantes, como, por exemplo, a razão da existência de pelos no 
Kawamoto, E. M.; Campos, L. M. L.

nariz e a origem do soluço, que surpreenderam os estudantes de tal forma que eles comentaram que contariam ao irmão ou aos pais aquela nova informação.

O gibi mobilizou os estudantes para o conhecimento, e Pizarro (2009, p. 37) descreve o significado desse recurso pedagógico:

Significativa parcela das contribuições das histórias em quadrinhos reside na função que as mesmas podem desempenhar para a aprendizagem de conteúdos procedimentais mais amplos, com pertinência e inserção em diferentes áreas curriculares. Deste modo, priorizar o ensino de conteúdos curriculares procedimentais, mediante a utilização de histórias em quadrinhos no ensino de ciências, poderia favorecer a extensão das funções deste recurso didático para outras áreas curriculares igualmente importantes neste período da educação básica obrigatória.

Com a leitura finalizada, os estudantes elogiaram novamente o material, afirmando que este era um material muito mais interessante para aprenderem do que a leitura simples de um texto. Foi aplicado um novo questionário, a fim de verificarmos a relevância do recurso utilizado.

As questões foram as seguintes: 1) Qual a sua opinião a respeito do gibi? 2) Você gostaria que tivessem mais gibis dessa natureza? Se sim, de qual assunto? 3) Qual parte do gibi você mais gostou? 4) Qual a parte do gibi que você menos gostou?

A análise das respostas ao questionário indicou que os assuntos que os estudantes acharam mais interessante na história em quadrinhos estavam relacionados ao conteúdo em que ocorreu erro no questionário prévio, o que demonstra que os estudantes tinham uma certa dificuldade em entender o assunto e que o material serviu para esclarecer dúvidas, como em relação à divisão do coração, onde os estudantes tinham dificuldades em entender tal divisão no órgão: "Agora consigo imaginar o coração como se ele tivesse quatro salas. Os átrios são como salas de espera para o sangue entrar no ventrículo"; "Agora toda vez que desenhar o coração vou lembrar q ele tem quatro separações e não duas como achava antes..."

Alguns estudantes que erraram a questão sobre o sistema nervoso no questionário inicial demonstraram no questionário pós-leitura um interesse maior pela parte da história em quadrinhos direcionada ao assunto: "Gostei muito da parte do sistema nervoso, porque ele controla tudo o que o corpo faz";"'Eu acho o sistema nervoso difícil, mas agora estou com mais vontade de estudar ele."

Quando os estudantes opinaram a respeito da história em quadrinhos, a totalidade afirmou que a considerava muito interessante e que gostou, pois era estimulante e algo diferente do que estavam acostumados a ter (leitura de textos somente).

Todos os estudantes pediram a elaboração de histórias em quadrinhos com outros assuntos de Ciências, pois acharam bem válida a experiência. Dentre os alunos, sete afirmaram que sentiram falta do sistema urinário no gibi e que gostariam de ler uma história com o sistema.

$\mathrm{Na}$ identificação da preferência por um determinado assunto, verificou-se que todos os sistemas tiveram a preferência de, pelo menos, um aluno, o que demonstra a variedade de opinião existente entre eles e a validade da história em quadrinhos elaborada. 
Em relação à questão "Qual parte do gibi você menos gostou?", a maioria das respostas foi genérica: "Gostei de tudo"; "Não tem parte que eu não gostei". Alguns estudantes manifestaram uma resposta contrária: "Não gostei muito do sistema digestório porque achei complicado" e "Não gostei do sistema nervoso tem muita coisa para ler" .

Os assuntos mencionados pelos estudantes que poderiam ser abordados em histórias em quadrinhos são: Tecidos do corpo humano, Recursos naturais, Cadeia alimentar, Doenças e Sistema Urinário.

Outro questionário foi entregue à professora, solicitando que ela indicasse: a adequação da linguagem utilizada na história aos alunos; a pertinência do conteúdo do gibi; a validade da utilização do gibi como material didático complementar; as formas de utilizar o gibi; sua opinião sobre o material e se já utilizou gibis como recurso didático.

A análise das respostas da professora ao questionário também foi realizada e indica que:

- a linguagem da história é de fácil entendimento; mais atraente";

- o conteúdo apresentado, "por se tratar de histórias em quadrinhos, tornou-se muito

- a utilização da história em quadrinhos como material didático complementar é válida, pois é "uma maneira lúdica de alcançar o aprendizado."

Ela considerou que o material:

“[...] como único meio e recurso para apresentar ao aluno seria pouco, mas como complemento da leitura e explicação é muito válido e interessante. Atualmente os vídeos estão competindo com os te xtos. A criança muitas vezes é atraída pelas imagens e os textos nos livros didáticos ainda permanecem como linguagem tradicional. O gibi vem ao encontro com a procura do educando por textos lúdicos nesta faixa etária entre 8 a 11 anos".

A professora afirmou que nunca havia utilizado história em quadrinhos e que vai "procurar mais materiais da natureza", pois acredita ser um recurso extremamente válido para o aprendizado dos estudantes de séries iniciais.

A partir dos dados obtidos, algumas alterações na proposta foram necessárias:

1) Diminuição da extensão do material: apesar da aprovação dos estudantes ao gibi, verificou-se que ele causou cansaço durante a leitura e certa dispersão durante a mesma.

2) Fragmentação: a organização do material, que continha vários sistemas incluídos, foi revista, e a história envolvendo um sistema passou a compor um gibi. A fragmentação do gibi, apesar de parecer contemplar o modelo tão criticado da separação de sistemas, não representa tal fato, uma vez que os gibis possuem conexões entre si, que remetem à integração dos sistemas do corpo humano.

O material impresso foi disponibilizado para a escola, num total de vinte exemplares. Ainda, o gibi pode ser acessado pela internet ${ }^{4}$.

\footnotetext{
${ }^{4}$ Disponível em: <http://www.ibb.unesp.br/\#!/museu-escola/emprestimos/lista-de-materiais-didaticos $>$ e <http://www.4shared.com/office/BFO8XWkq/GIBI_O_CORPO_HUMANO->. Acesso em: 21 jan. 2014.
} 
Kawamoto, E. M.; Campos, L. M. L.

\section{Considerações finais}

$\mathrm{Na}$ abordagem do tema corpo humano, torna-se fundamental a inclusão de metodologias didáticas que complementem e instiguem competências e habilidades dos estudantes, para que estes entendam o conteúdo e façam as reestruturações de conhecimentos prévios de modo adequado e real.

A aprendizagem depende muito das necessidades e interesses da criança (FRIEDMANN, 1998), devendo o professor considerar tais aspectos para decidir a melhor forma de utilizar os recursos didáticos disponíveis.

A utilização da história em quadrinhos "Corpo humano" se mostrou válida por diversos fatores: estímulo ao interesse dos estudantes pela leitura e conhecimento, praticidade da utilização, e uma nova alternativa de recurso complementar.

A história em quadrinhos envolve o aluno, possibilitando que o aprendizado seja diferenciado: o aluno aprende o conteúdo, desenvolve a capacidade criativa, pois a integração entre a realidade e a fantasia é favorecida, fazendo com que haja um "mergulho" dos estudantes no contexto da história, e se familiarizando e se apropriando da situação e do conhecimento disponibilizado pelo material.

Apesar de ser um material que desperta curiosidade, entende-se que a HQs não deve ser utilizada como fonte única para a apresentação do conteúdo, pois ela é considerada um recurso complementar e pode ser associada a outros recursos didáticos.

O professor, atualmente, necessita diversificar a aula de modo a torná-la atraente e profícua para o aprendizado, e as HQs auxiliam nesta meta. Conforme posicionamentos expressos na literatura, as histórias em quadrinhos possuem recursos (motivacionais, linguísticos) positivos que podem favorecer as práticas do professor, tornando-as acolhedoras, colhedoras, estimulantes e próximas dos interesses dos estudantes (PIZARRO, 2009).

Estudantes das séries iniciais necessitam e apreciam novos recursos de ensino, pois, nessa fase, é crucial que tal conhecimento seja construído de forma sólida, para que se tornem base ou, como indica Ausubel (1968 apud MOREIRA; MASINI, 1982), "subsunçores" para novos conhecimentos. $\mathrm{O}$ uso de HQs nessa situação torna-se conveniente, estimulante e válido, desde que adequadamente utilizado e proposto.

Destaca-se a necessidade de estímulo para o aprimoramento de práticas pedagógicas que envolvam maior uso de histórias em quadrinhos em diversas áreas da Educação, uma vez que o recurso é um importante estímulo para os estudantes dos anos iniciais, pois possibilitam a interação entre o conhecimento em Ciências e o processo de alfabetização.

\section{Referências}

BRASIL. Ministério da Educação. Secretaria de Educação Fundamental. Parâmetros curriculares nacionais: ciências naturais. Brasília, 1998. 
Histórias em Quadrinhos como recurso ...

CAMPOS, L. M. L. et al. Ciranda pedagógica: o lúdico e o ensino de ciências nos anos iniciais do ensino fundamental: uma proposta de investigação e de ação. In: PINHO, S. Z.; OLIVEIRA, J. B. B. (Org.). Núcleo de ensino da UNESP: artigos dos projetos realizados em 2008. São Paulo: Cultura Acadêmica: Universidade Estadual Paulista, 2011. p. 215-226. Disponível em: < http://unesp.br/prograd/Livro2008/sources/index.htm>. Acesso em: 25 out. 2013.

FANIZZI, S.; GIL, A. Ciências naturais: $4^{a}$ série. São Paulo: FTD, 2005. (Coleção porta aberta)

FISCARELLI, R. B. de O. Material didático: discursos e saberes. Araraquara: Junqueira \& Marin, 2008.

FONSECA, M. S. et al. Ciências para você - $5^{\circ}$ ano. 3. ed. Curitiba: Positivo, 2007.

FRIEDMANN, A. O direito de brincar: a brinquedoteca. São Paulo: Scritta, 1998.

GONÇALVES, R.; MACHADO, D. M. Comics: investigación de conceptos y de términos paleontológicos, y uso como recurso didáctico en la educación primaria. Enseñanza de las Ciencias, Barcelona, v. 23, n. 2, p. 263-274, 2005. Disponível em: <http://ddd.uab.es/ pub/edlc/02124521v23n2p263.pdf>. Acesso em: 25 out. 2013.

GONZÁLEZ-ESPADA, W. J. Integrating physical science and the graphic arts with scientifically accurate comic strips: rationale, description, and implementation. Revista Electrónica de Enseñanza de las Ciencias, Vigo, v. 2, n. 1, p. 58-66, 2003.

KAMEL, C. R. L. Ciências e quadrinhos: explorando as potencialidades das histórias como materiais instrucionais. 2006. 113 f. Dissertação (Mestrado em Ensino em Biociências e Saúde) - Instituto Oswaldo Cruz, Rio de Janeiro, 2006.

KAWAMOTO, E. M. As histórias em quadrinhos como recurso didático para o ensino do corpo humano em séries iniciais. 2009. 73 f. Trabalho acadêmico (Relatório de estágio) - Instituto de Biociências, Universidade Estadual Paulista, Botucatu, 2009.

KRASILCHIK, M. O professor e o currículo das ciências. São Paulo: EPU: EDUSP, 1987.

Prática de ensino de biologia. 4. ed. São Paulo: Edusp, 2005.

LISBÔA, E. S; BOTTENTUIT JUNIOR, J. B.; COUTINHO, C. P. Desenho em quadrinhos online: vantagens e possibilidades de utilização em contexto educativo. Revista Paidéi@, Santos, v. 2, n. 1, 2009.

MENEGHELLO, M. De olho no futuro: ciências - $4^{a}$ série. Campinas: Editora Quinteto, 2005.

MOREIRA, M. A.; MASINI, E. F. Aprendizagem significativa: a teoria de David Ausubel. São Paulo: Moraes, 1982.

OLIVEIRA, R. R. As finalidades do ensino de ciências naturais no discurso de professores das séries iniciais do ensino fundamental. Enseñanza de las Ciencias, Barcelona, p. 1154-1157, 2009. (Número extra). 
Kawamoto, E. M.; Campos, L. M. L.

OVIGLI, D. F. B.; BERTUCCI, M. C. S. A formação para o ensino de ciências naturais nos currículos de pedagogia das instituições públicas de ensino superior paulistas. Ciências \& Cognição, Rio de Janeiro, v. 14, n. 2, p. 194-207, 2009. Disponível em: <http:// www.cienciasecognicao.org/revista/index.php/cec/article/download/215/114 >. Acesso em: 21 jan. 2014.

PAIS, L. C. Uma análise do significado da utilização de recursos didáticos no ensino da geometria. In: REUNIÃO ANUAL DA ANPED, 23., 2000, Caxambú. Anais...

Disponível em: <http://23reuniao.anped.org.br/textos/1919t.PDF>. Acesso em: 28 out. 2013.

PIZARRO, M. V. Histórias em quadrinhos e o ensino de ciências nas séries iniciais: estabelecendo relações para o ensino de conteúdos curriculares procedimentais. 2009. $188 \mathrm{f}$. Dissertação (Mestrado em Educação para a Ciência) - Faculdade de Ciências, Universidade Estadual Paulista, Bauru, 2009.

RABELLO, S. H. dos S. A criança, seu corpo, suas idéias. Ensino em Re-vista, Uberlândia, v. 3, n. 1, p. 15-29, jan/dez, 1994.

RITTES, A. As histórias em quadrinhos na escola: a percepção de professores de ensino fundamental sobre o uso pedagógico dos quadrinhos. Dissertação (Mestrado em Educação para Ciência) - Universidade Católica de Santos, Santos, 2006.

SOARES, A. H. M. A química e a imagem da ciência e dos cientistas na banda desenhada: uma análise de livros de B. D. e de opiniões e interpretações de investigadores, professores de C. F. Q. e alunos do $3^{\circ}$ ciclo. 2004. 313 f. Dissertação (Mestrado em Química) - Universidade de Minho, Braga, 2004. Disponível em: < http://hdl.handle.net/ 1822/590>. Acesso em: 20 out. 2013

TESTONI, L. A. Um corpo que cai: as histórias em quadrinhos no ensino de física. 2004. 158 f. Dissertação (Mestrado em Educação) - Faculdade de Educação, Universidade de São Paulo, São Paulo, 2004.

VERGUEIRO, W. Como usar histórias em quadrinhos na sala de aula. São Paulo: Contexto, 2004.

VÍLCHEZ-GONZÁLEZ, J. M.; PERALES-PALACIOS, F. J. Image of science in cartoons and its relationship with the image in comics. Physics Education, London, v. 41, n. 3, p. 240-249, 2006. Disponível em: <http://www.iop.org/EJ/abstract/0031-9120/41/ 3/006/> Acesso em: 28 out. 2013.

WORNER, C. H. ; ROMERO, A. Una manera diferente de enseñar física: física y humor. Enseñanza de las Ciencias, Barcelona, v. 16, n. 1, p. 187-192. 1998. Disponível em: <http://www.raco.cat/index.php/Ensenanza/article/view/83244/108227> Acesso em 28 out. 2013.

ZORZETTO, N. L. Curso de anatomia humana. 7. ed. Bauru: Jalovi, 1999.

Artigo recebido em 31/01/13. Aceito em 04/10/13. 